\title{
Kinetics of Isothermal Degradation Studies in Adhesives by Thermogra- vimetric Data: Effect of Hydrophilic Nanosilica Fillers on the Thermal Properties of Thermoplastic Polyurethane-Silica Nanocomposites
}

\author{
Jose Vega-Baudritt $^{\mathrm{a}, \mathrm{d}, *}$, Maria Sibaja-Ballestero ${ }^{\mathrm{a}}$, Patricia Vázquez ${ }^{\mathrm{c}}$, Santiago Nuñez ${ }^{\mathrm{d}}$, Jose M. \\ Martín-Martínez ${ }^{\mathrm{b}}$, Luis Benavides-Rodríguez ${ }^{\mathrm{a}}$ \\ ${ }^{a}$ Polymer Laboratory - Poliuna, Universidad Nacional, 86-3000 Heredia. Costa Rica. ${ }^{b}$ Adhesion and Adhesives \\ Laboratory, University of Alicante, 03080 Alicante, Spain. ${ }^{c}$ Research and Development Centre for Applied Sciences \\ (Cindeca), Conicet-UNLP, $47 n$ 257, B1900AJK La Plata, Buenos Aires. Argentina. ${ }^{d}$ National Nanotechnology \\ Laboratory -Lanotec-Cenat, San José, Costa Rica
}

Received: February 22, 2008; Accepted: June 8, 2008; Revised: July 22, 2008

\begin{abstract}
The kinetics of thermal degradation process on thermoplastic polyurethanes (TPUs) adhesives with hydrophilic nanosilicas was studied using isothermal thermogravimetric analysis within the temperature range from $360{ }^{\circ} \mathrm{C}$ to $460{ }^{\circ} \mathrm{C}$ in nitrogen. The effect of nanosilicas with different hydrophilic degree in the thermoplastic polyurethanes was investigated. It was found that the thermoxidative degradation of polyurethane-silica nanocomposites takes place in one step. An analysis of the isothermal methods to evaluate kinetic parameters of decomposition of solids from isothermal thermogravimetric data is presented. Patents WO07146353A2 and US20070292623A1 have some relevant information about the topic develop in this study, because the principle in both cases relies on the interactions between reactive groups in the polymer (TPUs) and the silanol in the silica nano-particles.
\end{abstract}

Keywords: Kinetic analysis, isothermal degradation, adhesives, hydrophilic nanosilica, polyurethane-silica, nanocomposites, thermogravimetric analysis.

\section{INTRODUCTION}

Thermoplastic polyurethanes (TPUs) constitute a multipurpose group of phase-segmented polymers that have good mechanical and elastic properties and hardness [1]. TPUs usually exhibit a two-phase microstructure, which arises from the chemical incompatibility between the soft and the hard segments. The hard (rigid) segment segregates into a glassy or semicrystalline domain and the polyol soft segments form amorphous or rubbery matrices, in which the hard segments are dispersed. Many factors influence in the separation of the phases such as molecular weight, segmental length, crystallizability of the segment, overall composition and intra- and inter-segments interactions [1]. Fumed nanosilicas are added to increase the thermal, rheological and mechanical properties of TPUs [2-6]. Other studies have been developed by different researchers with PU (polyurethane), improving the chemical and physical properties of this polymers and changing the polyurethane to thermoset plastics [7]. Only thermoplastic polyurethanes are used in this study.

When hydrophilic fumed nanosilica is added, the degree of the phase separation increases due to the hydrogen-bond interaction between silanol groups on the nanosilica surface and the soft segments of TPUs. Therefore, the segmental incompatibility on TPUs is increased in the presence of the hydrophilic nanosilicas. Recent studies have shown that the use of this kind of materials is able to form hydrogen bonds resulting in less direct interactions between phases and

\footnotetext{
*Address correspondence to this author at the Polymer Laboratory Poliuna, Universidad Nacional, 86-3000 Heredia. Costa Rica;

Tel/Fax: (506) 2277 3557; E-mail: jvegab@una.ac.cr
}

causing a higher phase separation. Furthermore, the interactions between silanol and carbonyl groups are weaker than those between $\mathrm{NH}$ and ester-carbonyl groups; silica addition increases the polyester chain mobility and it allows better molecular ordering with respect to TPUs without silica [811]. This kind of interaction has been used in the formulation of coating where the interaction between reactive groups and silica nano-particles provide enhanced scratch and resistance to deformation $[12,13-15]$.

In this study, nanosilica treated with silanes (WackerChemie) was used to decrease its silanol group content. Thus, different TPU adhesives containing $10 \mathrm{wt} \%$ fumed silica, with different degree of silanization $(100,57.5$ and 15 $\%$ ) were prepared and later characterized by thermogravimetric analysis (TGA and DTGA). Finally, in order to study the effect of this kind of silicas in TPUs, isothermal methods were used for evaluating thermal degradation kinetic parameters from isothermal thermogravimetric data.

Recent papers show the results of evaluating these samples using thermal, rheological and mechanical analysis, and adhesion tests $[14,15]$.

\section{EXPERIMENTS}

\section{Materials}

Different fumed silicas (nanosilicas) manufactured by Wacker-Chemie (Burghausen, Germany) were used. A fully silanized nanosilica (HDK N20, Wacker Chemie) was progressively modified by chemical reaction with dimethyldichlorosilane (DMCS) (Scheme 1). 
<smiles>C[Si](C)(Cl)O[Si](C)(C)O[Si](C)(C)[CH+][OH+]</smiles>

Scheme 1.

The degree of silanization was decreased between 15.0 and $57.5 \%$. Primary nominal particle size in all nanosilicas was $7 \mathrm{~nm}$. Table 1 shows the nomenclature of nanosilicas and some of their characteristics provided by Wacker-Chemie. According to Wacker-Chemie, the nominal specific surface area of all nanosilicas was $200 \mathrm{~m}^{2} / \mathrm{g}$.

Table 1. Some Characteristics of Fumed Nanosilicas According to Wacker-Chemie

\begin{tabular}{|c|c|c|}
\hline Sample & $\mathrm{SiOH}(\%)$ & $\mathrm{mmol} \mathrm{SiOH} / \mathrm{g}_{\text {nanosilica }}$ \\
\hline HDK N20 & 100 & 0.60 \\
\hline HDK H20 & 57.5 & 0.34 \\
\hline HDK H20RD & 15.0 & 0.09 \\
\hline
\end{tabular}

TPUs were prepared using the prepolymer method [14, 15]. The prepolymer was obtained by reacting the polyadipate of 1,4-butanediol ( $M_{\mathrm{w}}=2440$ Daltons $)$ with 4,4diphenyl methane di-isocyanate - MDI. An isocyanate/ macroglycol equivalent ratio of 1.05 was used. 1,4butanediol was used as chain extender. High purity solid MDI was supplied by Aldrich (Cat. 25.643-9) as well as a mixture of $98 \mathrm{wt} \%$ of the $4,4^{\prime}$-isomer and $2 \mathrm{wt} \%$ of the $2,4^{\prime}$ isomer. The NCO content of the prepolymer was determined by titration with dibutylamine (UNE-EN 1242 standard). Polyadipate of 1,4-butanediol (Hoopol F-530) was supplied by Hooker S.A. (Barcelona, Spain) and was heated for 4 hours at $70^{\circ} \mathrm{C}$ under reduced pressure (5 Torr) in order to remove residual water. The 1,4-butanediol supplied by Aldrich (Cat. B8, 480-7) was dried using $4 \AA$ molecular sieves.

The reaction temperature was kept below $65^{\circ} \mathrm{C}$ under a stirring speed of $80 \mathrm{rpm}$, hence avoiding cross-linking reactions during polyurethane synthesis. Polyurethane synthesis was carried out in a dry nitrogen atmosphere in order to avoid water in the reactor. The prepolymers containing unreacted isocyanate ends were completely reacted with the necessary stoichiometric amount of 1,4-butanediol. The reaction time was 2 hours. TPUs were annealed in an oven at $80^{\circ} \mathrm{C}$ for 12 hours (curation time).

TPU adhesive solutions were prepared by mixing $20 \mathrm{wt} \%$ solid polyurethane and $2 \mathrm{wt} \%$ nanosilica with 2-butanone in a Dispermix DL-A laboratory mixer equipped with a Cowles mechanical stirrer (diameter $=50 \mathrm{~mm}$ ) and a water jacket to maintain the temperature at $25^{\circ} \mathrm{C}$ during process. Adhesive preparation was carried out in two consecutive stages: $i$ ) the nanosilica was mixed for $15 \mathrm{~min}$ at $2500 \mathrm{rpm}$ with a $1 / 3$ volume of butanone required by the adhesive. $i$ i) the TPUs and $2 / 3$ volumes of butanone were added to the previous solution, stirring the mixture for 2 hours at $2000 \mathrm{rpm}$. TPU adhesive solutions were kept in a hermetic container until use. A TPU adhesive solution without silica was also prepared as a control solution. Most of the properties of the polyurethanes were measured using solid films, which were prepared by placing approximately $100 \mathrm{~cm}^{3}$ of adhesive solution in a mould and allowing slow evaporation of the solvent at room temperature for 2 days. The thickness of the obtained polyurethane films ranged in between $0.7 \mathrm{~mm}$ and $0.9 \mathrm{~mm}$.

The nomenclature of the polyurethane-nanosilica mixtures was PU0 (TPUs without silica), PU15, PU57.5 and PU100 for the TPU's containing nanosilicas with $15 \%$, $57.5 \%$ and $100 \%$ of weight silanol groups, respectively.

\section{Experimental Techniques}

Isothermal thermogravimetric studies were carried out on a Mettler TGSDTA thermobalance (model 851e/1600/LF) in nitrogen flow at a rate of $100 \mathrm{~mL} / \mathrm{min}$. Isothermal conditions were maintained stable during 30 minutes and then samples (4-5mg) were heated until $800^{\circ} \mathrm{C}$. The heating rate was $10^{\circ} \mathrm{C} / \mathrm{min}$ in nitrogen.

Kinetic parameters were studied using the degradation standard equation, the Arrhenius method, the Klaric method and the MacCallum method [16-27].

\section{RESULTS AND DISCUSSION}

\section{Thermal Analysis}

The thermogravimetric analysis (TGA) results of samples in nitrogen are shown in Fig. (1).

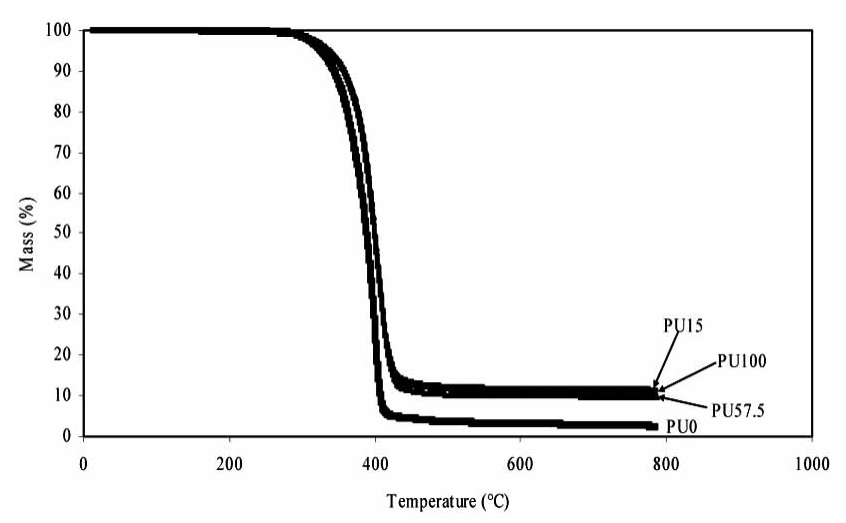

Fig. (1). TGA curves of TPU's samples with and without nanosilica at $10^{\circ} \mathrm{C} / \mathrm{min}$, in nitrogen.

In all polyurethane samples, thermal degradation starts at $380^{\circ} \mathrm{C}$ (onset temperature- $\mathrm{T}_{\mathrm{i}}$ ) and proceeds in one step. At $500^{\circ} \mathrm{C}$, decomposition can be considered as complete. The temperatures of the maximum rates of weight loss ([dw/dT $]_{\max }$ ) were obtained using DTGA (Fig. 2).

DTGA curves show similar thermal stability for TPUs with nanosilica, higher than that in PU0. According with the segmental nature of thermoplastic polyurethanes, samples show two events for degradation. According to some studies of polyurethane, urethane bonds present lower stability than structures with soft segments (polyols) [16-18]. Therefore, in PU0 a first peak related to the urethane linkages degradation is observed at $380^{\circ} \mathrm{C}$. The second peak at $416^{\circ} \mathrm{C}$ is related 


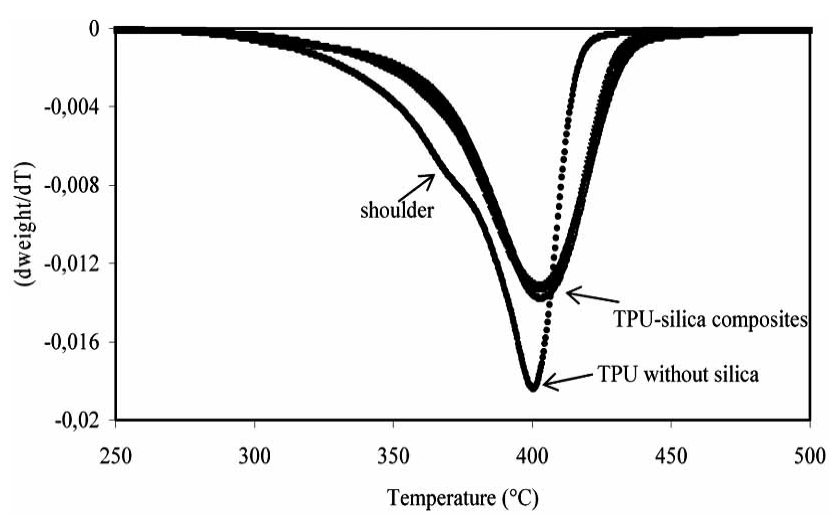

Fig. (2). DTGA curves of TPU samples with and without nanosilica at $10 \mathrm{C} \% \mathrm{~min}$, in nitrogen.

with the poliol chain scission. In TPU-silica composites, both degradations are overshadowed. The analysis shows that nanoadditives increased the thermal stability of TPUs.

In all samples, no significant peaks over the maximum rates of weight-loss temperature were observed. TGA and DTGA data are summarized in Table $\mathbf{2}$.

Table 2. Thermal Properties of Polyurethane-Silica Composites in Nitrogen at $10^{\circ} \mathrm{C} / \mathrm{min}$ Measured by TGA.

\begin{tabular}{|c|c|c|}
\hline \multirow{2}{*}{ Sample } & \multicolumn{2}{|c|}{ Temperature $\left({ }^{\circ} \mathbf{C}\right)$} \\
\cline { 2 - 3 } & $\begin{array}{c}\text { Maximum rates of weight loss } \\
\left([\mathbf{d} \text { w/dT }]_{\text {max }}\right)\end{array}$ & Onset $\left(\mathbf{T}_{\mathbf{i}}\right)$ \\
\hline \hline PU0 & 416 & 380 \\
\hline PU15 & 418 & 384 \\
\hline PU57,5 & 419 & 386 \\
\hline PU100 & 422 & 390 \\
\hline
\end{tabular}

The thermal stability of TPU-silica nanocomposites is related with the degree of phase separation in the polyurethanes. Recent studies [10,11, 14, 15] have demonstrated that the addition of fillers that able to form hydrogen-bondssuch as silica- results in less direct interactions between phases, thus causing a higher degree of phase separation in the polyurethane. On the other hand, the interactions between the silanol groups and the carbonyl groups in the polyurethane are weaker than those between the N-H and ester-carbonyl groups, and consequently silica addition increases the polyester chain mobility in polyurethane by allowing the creation of more ordered phases with respect to the polyurethane without silica.

\section{Kinetic analysis}

Under isothermal conditions, the fractional reaction-time $(\alpha-t)$ curves are expressed as is indicated by equation 1 .

$g(\alpha)=k t$ where $k$ is the rate constant and the function $g(\alpha)$ depends on the mechanism controlling the reaction [19]. The decomposition ratio $(\alpha)$ was determined using equation 2 .

$\alpha=\frac{w_{i}-w(t)}{w_{i}-w_{f}}$

where $w_{i}$ is the initial mass, $w(t)$ is the mass in time $t$ and $w_{f}$ is the final mass. Figs. (3) to (6) show the plots for the isothermal decomposition of TPU-silica nanocomposites. The decomposition ratio increased when the temperature of the isothermal thermogravimetric analysis increased. At $440^{\circ} \mathrm{C}$ and $460^{\circ} \mathrm{C}$, the decomposition ratio decreased, indicating that complete thermal decomposition of the polyurethanes was reached.

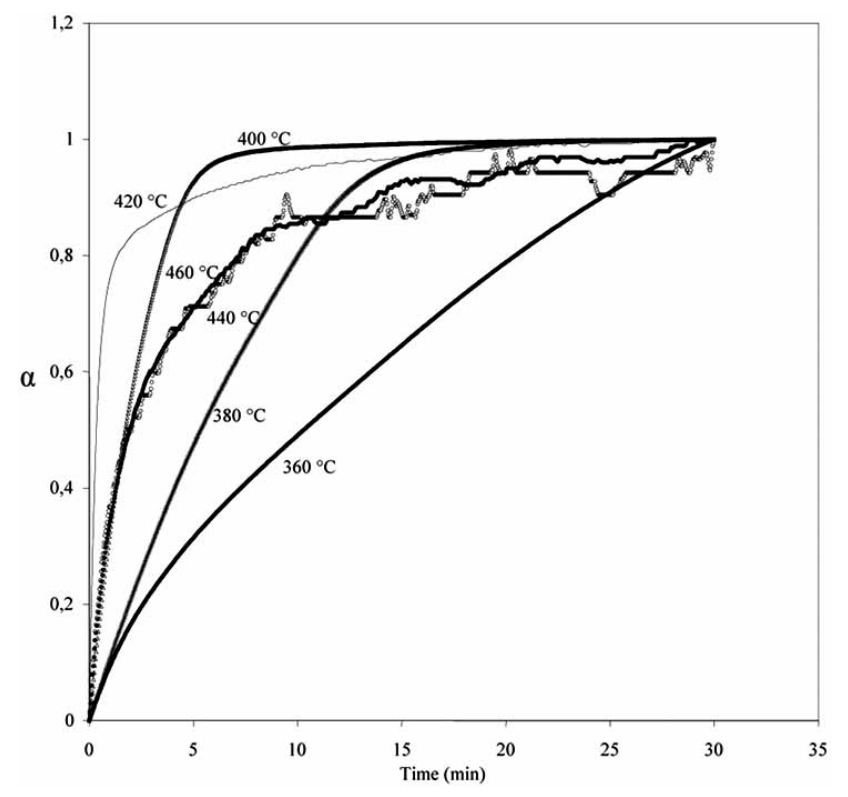

Fig. (3). Plot of isothermal decomposition for PU0.

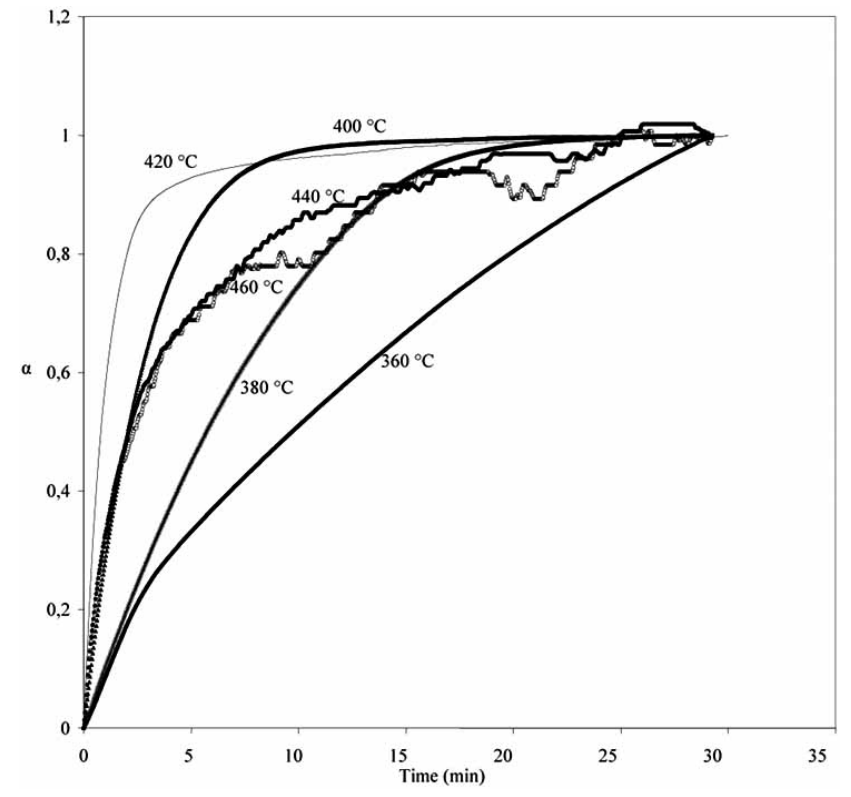

Fig. (4). Plot of isothermal decomposition for PU15. 


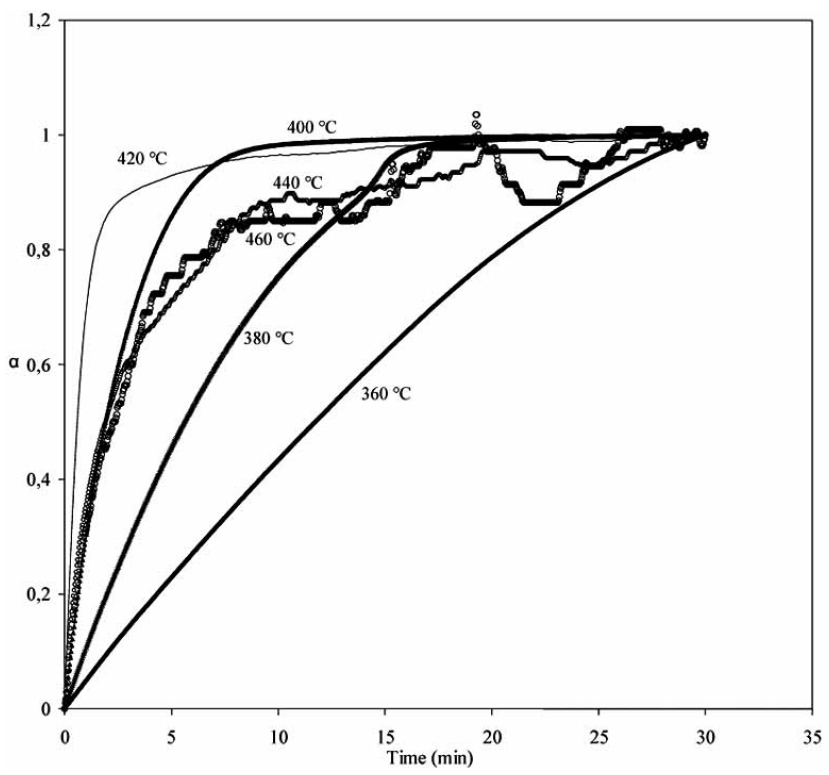

Fig. (5). Plot of isothermal decomposition for PU57.5

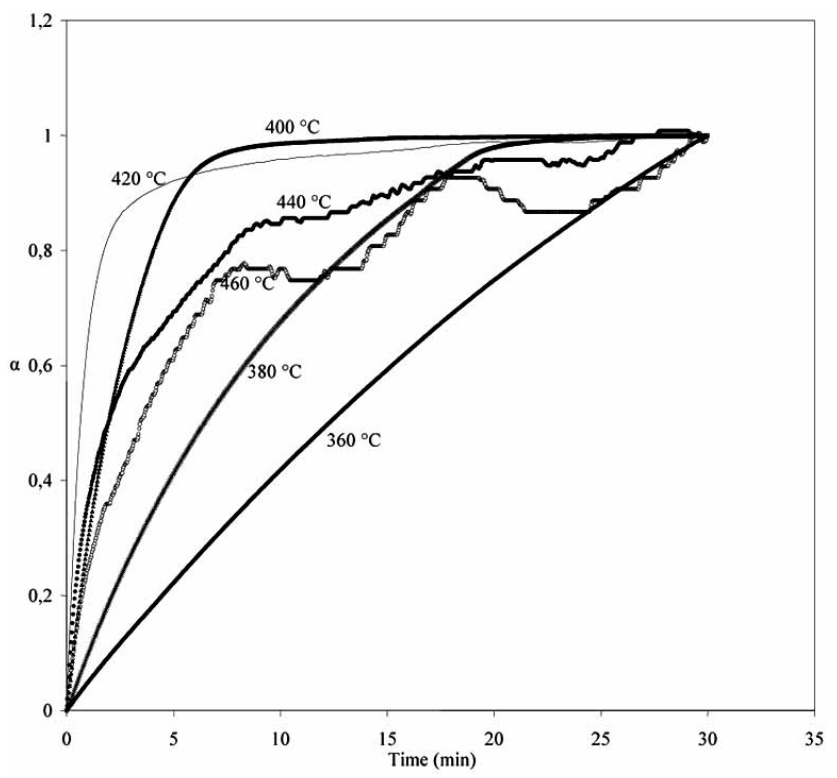

Fig. (6). Plot of isothermal decomposition for PU100.

Kinetic parameters from TGA data may yield additional insight into the mechanism of thermal degradation. It is generally accepted that materials obey equation 3 [27].

$$
\frac{d \alpha}{d t}=k(T)(1-\alpha)^{n}
$$

where $n$ is the order of the reaction. The temperature dependence in equation 3 is defined via the reaction rate term $k$ which is assumed to be in the Arrhenius form (equation 4),

$k=A e^{\frac{-E_{a}}{R T}}$

where $A$ is the pre-exponential factor, $E_{a}$ is the activation energy and $R$ is the gas constant. Equation 3 needs to be fitted against experimental data from the isothermal thermogravimetric analysis in order to obtain $n$ and $k$. Repeating the process at several temperatures leads to $k(T)$, which can be used in equation 4 to obtain $A$ and $E_{a}$ for degradation. Plotting $\ln [k(T)]$ against the reciprocal temperature Fig (7) yields a straight line with a slope proportional to the activation energy. The intersection of them yields the preexponential factor.

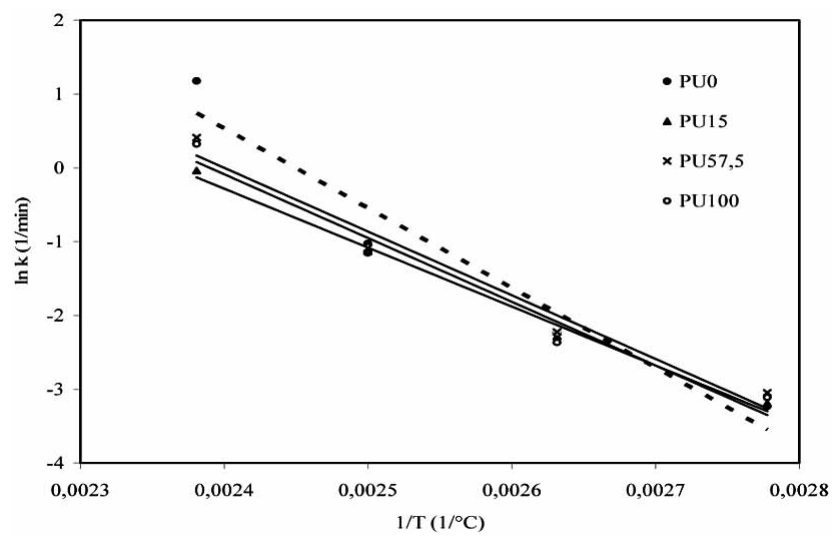

Fig. (7). Linear dependence in the Arrhenius method used for TPUsilica nanocomposites.

In order to compare the kinetic parameters, the results of the Arrhenius method are summarized in Table 3. TPUnanosilica nanocomposites show a smaller activation energy and pre-exponential factor in comparison with PU0. In TPUnanosilica samples, both parameters raise with the increase of the silanol group contents on the silica surface used in the nanocomposites. This correlated increment implies that any increase in the activation energy is accompanied by an increase in the pre-exponential factor to keep the rate constant nearly unchanged. This tendency is known as the kinetic compensation effect (KCE) [20,21].

Table 3. Kinetic Parameters for TPU-Silica Nanocomposites (Arrhenius Method)

\begin{tabular}{|c|c|c|}
\hline Sample & $\mathbf{E}_{\mathbf{a}}(\mathbf{k J} / \mathbf{m o l})$ & $\ln \mathbf{A}$ \\
\hline \hline PU0 & 89.8 & 26.5 \\
\hline PU15 & 66.4 & 18.9 \\
\hline
\end{tabular}

In order to obtain $k$ and $n$, the kinetic standard equation (equation 5) was used. Assuming a kinetic model function $f$ $(\alpha)=(1-a)^{n}$, equation 5 can be transformed into equation 6 $[22,23]$

$\ln \left(\frac{d \alpha}{d t}\right)=\ln [k(T)]+\ln [f(\alpha)]$
$\ln \left(\frac{d \alpha}{d t}\right)=\ln [k(T)]+n \ln (1-\alpha)$

Plotting $\ln (d \alpha / d t)$ against $\ln (1-\alpha)$ yields a straight line with slope proportional to the reaction order and the intersection of the yield rate constant. Fig (8) and Fig (9) 
show the comparison of the rate constant and reaction order obtained from the kinetic standard equation respectively.

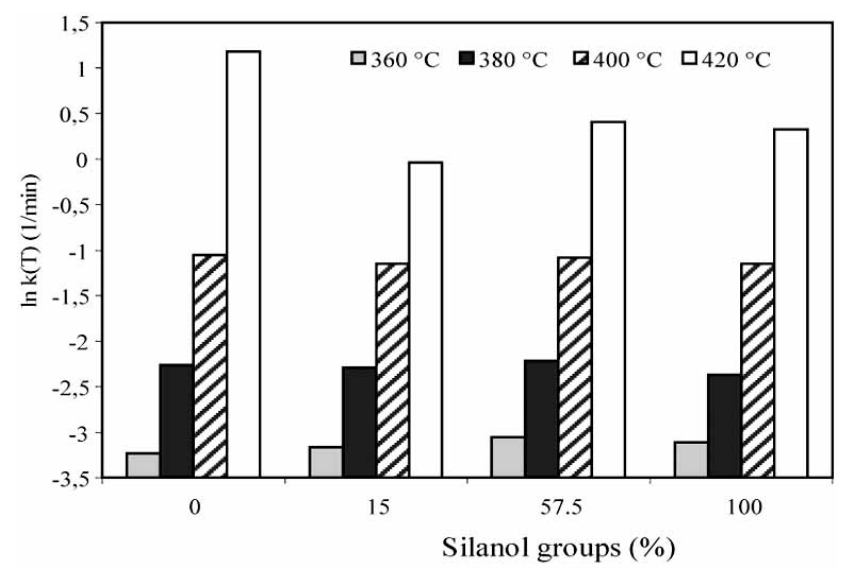

Fig. (8). Comparison of the rate constant obtained from the kinetic standard equation.

When the temperature of the isothermal analysis was incremented during the experiment, an increase in the rate constant was observed Fig. (8). At $420^{\circ} \mathrm{C}$, important changes appear in the rate constant. As mentioned above, incorporation of nanosilica in TPUs increases the temperature of the maximum rate for weight loss $\left([d w / d T]_{\max }\right)$ and for the onset temperature $\left(T_{i}\right)$. Furthermore, nanosilica in TPUs decreases the kinetics of decomposition due to more interactions among the polyurethane soft segments. The silanol groups on the silica surface enhance phase separation and improve its thermal properties. In fact, PU0 has the lowest temperature of the maximum rate for weight loss and onset temperature, and the highest degradation rate constant.

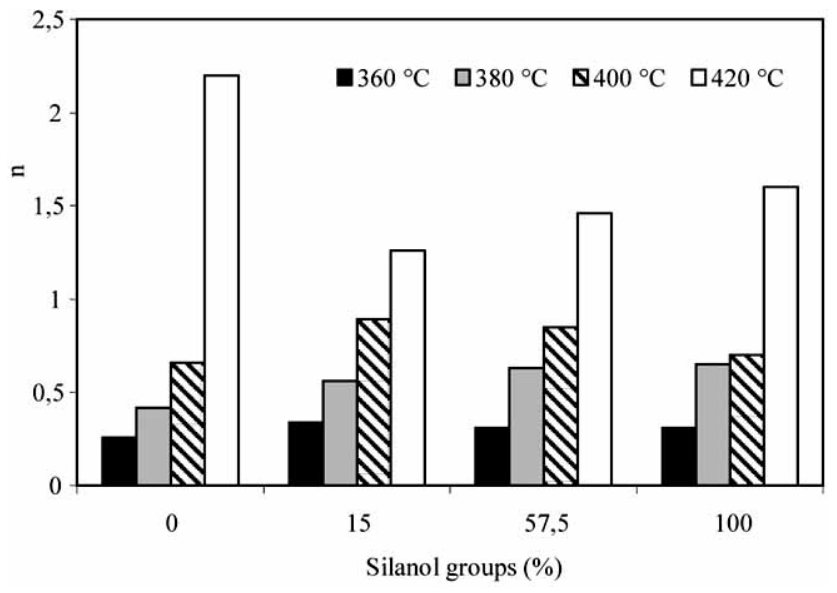

Fig. (9). Comparison of the reaction order obtained from the kinetic standard equation.

In the comparison of TPU-nanosilica samples, PU15 shows the smallest rate constant. PU100 and PU57.5 exhibit a similar rate constant. Therefore, an increase of silanol groups in the nanosilica surface enhances the polymer thermal degradation rate.
Finally, at low temperatures the reaction order was unaffected in samples with nanosilica. When the temperature approaches that of degradation $\left(420^{\circ} \mathrm{C}\right)$, the reaction order increases up to 1.5. In addition, PU0 sample shows a reaction order of 2 . Therefore, fumed nanosilica in TPUnanocomposites changes the thermal degradation mechanism.

Another isothermal technique is the so-called stationary point method or Klaric method [24, 25]. The decomposition ratio $(\alpha)$ was redefined as shown in equation 7 .

$\alpha=\frac{w_{i}-w(t)}{w_{i}}$

The stationary point is defined on the curve of $d \alpha / d t$ versus $t$ as the point where the rate $V$ reaches a maximum value $\left(V_{\max }\right)$. The activation energy can be obtained from equation 8 with respect to $V_{\max }$. Fig. (10) shows the linear dependence in the Klaric method used for TPU-silica nanocomposites.

$\frac{d \ln V_{\max }}{d\left(\frac{1}{T}\right)}=\frac{d \ln k}{d\left(\frac{1}{T}\right)}=-\frac{E_{a}}{R}$

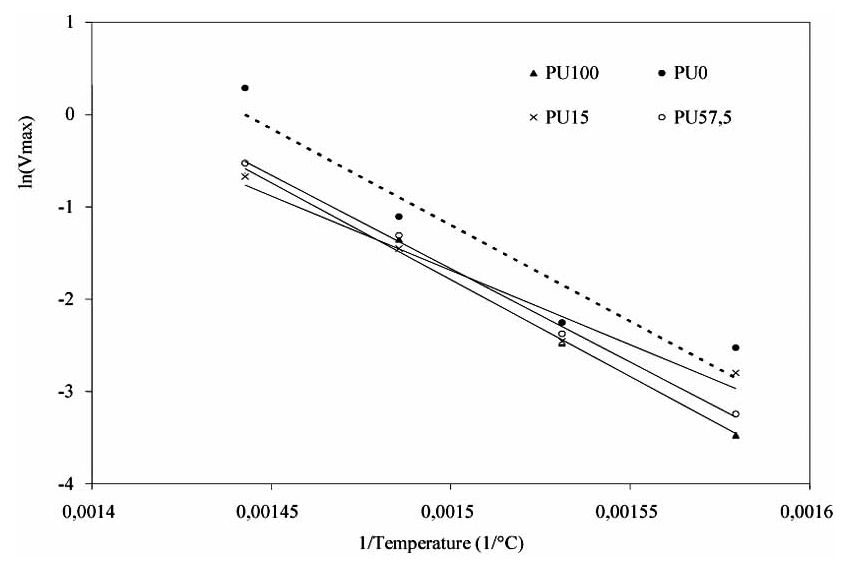

Fig. (10). Linear dependence in the Klaric method used for TPUsilica nanocomposites.

Table 4 shows the activation energy obtained from Klaric method. The values of the activation energies shown in Table $\mathbf{3}$ are roughly twice those found using the Arrhenius method. This discrepancy between the $E_{a c t}$ values can be attributed to the assumptions used during treatment of data. It is difficult to determine maxima points at the lowest temperatures using the Klaric method.

MacCallum develop another method for analysis of isothermal degradation. The decomposition fraction $(\alpha)$ was redefined as show in equation 7. MacCallum proposed a function $F$ and a first-order reaction modelled by equation 9 $[27,28]$. 
Table 4. Activation Energy for TPU-Silica Nanocomposites (Klaric Method)

\begin{tabular}{|c|c|}
\hline Sample & $\mathbf{E}_{\mathbf{a}}(\mathbf{k J} / \mathbf{m o l})$ \\
\hline \hline PU0 & 173.4 \\
\hline PU15 & 133.9 \\
\hline PU57.5 & 168.1 \\
\hline PU100 & 172.5 \\
\hline
\end{tabular}

$\frac{d(1-\alpha)}{d t}=k F(1-\alpha)$

Then, integrating equation 9 and using equation 4 equation 10 is obtained.

$F(1-\alpha)=A e^{-\frac{E a}{R T}} t$

Over some temperature range, $F(1-\alpha)$ should be constant for a given value of $\alpha$. Rewritting equation 10 leads to equation 11 .

$\frac{E_{a}}{R}+\ln [F(1-\alpha)]-\ln A=\ln t$

Plotting $\ln t$ against 1/T (for fixed values of $\alpha$ ) yields a straight line with slope proportional to $E_{a}$. Moreover, plotting intersections at several temperatures against $\alpha$ and extrapolating to zero yields the value of $A$ (equation 12).

Intersection $=\ln [F(1-\alpha)]-\ln A$

Fig. (11) shows the linear dependence in the MacCallum method used for characterizing TPU-silica nanocomposites. In order to compare the kinetic parameters, the results of the MacCallum method have been summarized in Table 5. Comparing with the results of the Klaric method (Table 4), the tendency and values obtained are similar. In both cases, activation energy and $A$ change depending on the silanol groups content on the nanosilica surface.

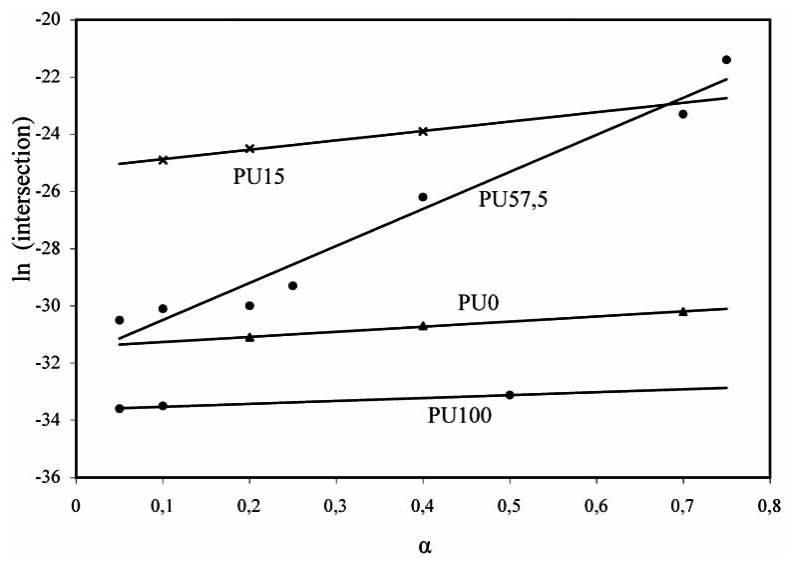

Fig. (11). The linear dependence in the MacCallum method used for TPU-silica nanocomposites.
Table 5. Activation Energy for TPU-Silica Nanocomposites (MacCallum Method)

\begin{tabular}{|c|c|c|}
\hline Sample & $\mathbf{E}_{\mathbf{a}}(\mathbf{k J} / \mathbf{m o l})$ & $\ln \boldsymbol{A}$ \\
\hline \hline PU0 & 177.4 & 31.4 \\
\hline PU15 & 140.6 & 25.2 \\
\hline PU57.5 & 163.3 & 31.8 \\
\hline PU100 & 176.9 & 33.6 \\
\hline
\end{tabular}

\section{CURRENT \& FUTURE DEVELOPMENTS}

Isothermal decomposition kinetics of the thermal degradation process in thermoplastic polyurethanes (TPUs) with hydrophilic nanosilicas was studied by thermogravi-metric analysis. Addition of nanosilicas improved the thermal properties of thermoplastic polyurethanes due to the creation of hydrogen bonds among the soft segments of polyurethane. Nanosilica disrupted the compatibility between the hard and soft segments, favouring the degree of phase separation in the polyurethanes. The highest silanol content in the nanosilica produced a maximum degree of phase separation.

Kinetic parameters from TGA data yield additional insight about the mechanism of thermal degradation. In order to analyze isothermal thermogravimetric data, some models of thermal degradation were used. An increase of the temperature in isothermal analysis produced an increment in the rate constant. Furthermore, nanosilica in TPUs decreases the kinetics of decomposition due to the increase of the interaction between the polyurethane soft segments. Nevertheless, an increase of the silanol groups in nanosilica surface enhanced the polymer thermal degradation rate. Also, these studies showed an increment in $E_{a}$ and $A$ values produced by the increase of the content of silanol groups in the silica surface. However, TPUs without nanosilica showed higher $E_{a}$ and $A$ values. This suggests that although it degrades at a higher rate with lower initial degradation and at a maximum rate within decomposition temperatures, it needs higher activation energy for degradation. The latter has been explained as a smaller segregation of the phases in TPUs without silica, enhancing the interaction among the hard and soft segments of TPUs through hydrogen bonds. It was necessary to apply more energy for their thermal degradation.

The study of the interaction between different polymers and nano-particles is a common task in the process of improving materials for different target applications, in this particular case for producing an enhanced adhesive. Another area that might benefit from this technology is car painting and painting in general due to the principle behind the interactions between polymers and the silanol groups, leading to significant improvements in the properties of paints.

\section{REFERENCES}

[1] Oertel G. In: Polyurethane Handbook $2^{\text {nd }}$, Hanser: New York, 1993, 7; Chapter 2.

[2] Maciá-Agulló TG, Fernández-García JC, Pastor-Sempere N, Orgilés-Barceló AC, Martín-Martínez JM. Addition of Silica to Polyurethane Adhesives. J Adhesion 1992; 38: 31-53. 
[3] Jaúregui-Beloqui B, Fernández-García JC, Orgilés-Barceló AC, Mahiques-Bujanda MM, Martín-Martínez JM. Thermoplastic polyurethane-fumed silica composites: Influence of the specific surface of fumed silica on the viscoelastic and adhesion properties. J Adhes Sci Technol 1999; 13: 695-711.

[4] Jaúregui-Beloqui B, Fernández-García JC, Orgilés-Barceló AC, Mahiques-Bujanda MM, Martín-Martínez JM. Rheological properties of thermoplastic polyurethane adhesive solutions containing fumed silicas of different surfaces areas. Int J Adhes Adhes 1999; 19: 321-328.

[5] Torró-Palau A, Fernández-García JC, Orgilés-Barceló AC, MartínMartínez JM. Characterization of polyurethanes containing different silicas. Int J Adhes 2001; 21: 1-9.

[6] Pérez-Limiñana MA, Torró-Palau AM, Orgilés-Barceló AC, MartínMartínez JM. Rheological properties of polyurethanes adhesives containing silica as filler; influence of the nature and surface chemistry of silica. Macromol Symp 2001; 169: 191-196.

[7] Limerkens, D., Lindsar, C., Mijs, C., Woutters, S.: WO07144292A1 (2007).

[8] Sánchez-Adsuar MS, Papón E, Villenave J. Influence of the prepolymerization on the properties of thermoplastic polyurethane elastomers. Part I. Prepolimerization characterization. J Appl Pol Sci 2000; 76: 1596-1601.

[9] Tien Y and Wei K. Hydrogen bonding and mechanical properties in segmented montmorillonite/polyuretane nanocomposites of differenthard segment ratios. Polymer 2001; 42: 3213-3221.

[10] Nunes RCR, Fonseca JLC, Pereira MR. Polymer-filler interactions and mechanical properties of a polyurethane elastomer. Polym Test 2000; 19: 93-103.

[11] Nunes RCR, Pereira RA, Fonseca JLC, Pereira MR. X-ray studies on composition of polyurethane and silica. Polym Test 2001; 20: 707-712.

[12] Lin, J.: WO07146353A2 (2007).

[13] Lin, J.: US20070292623A1 (2007)

[14] Vega-Baudrit J, Sibaja-Ballestero M, Vázquez P, Torregrosa-Maciá R, Martín-Martínez JM. Properties of thermoplastic polyurethane adhesives containing nanosilicass with different specific surfaces area and silanol content. Int J Adhes Adhes 2006; 27: 469-479.

[15] Navarro-Bañon V, Vega-Baudrit J, Vázquez P, Martín-Martínez JM. Interactions in nanosilica-polyurethane composites evidenced by plate-plate rheology and DMTA. Macromol Symp 2005; 221: 1-10.
[16] Ravey M and Pearce EM. Flexible polyurethane foam. I Thermal decomposition of a polyether-based, water-blown commercial type of flexible polyurethane foam. J App Polym Sci 1997; 63: 47-74.

[17] Semsarzadeh MA and Navarchian AH. Effects of $\mathrm{NCO} / \mathrm{OH}$ ratio and catalysis concentration on structure, thermal stability and crosslink density of poly(urethane-isocyanurate). J Appl Pol Sci 2003; 90: 963-972.

[18] Araújo RCS, Pasa VMD. Thermal study of polyurethane elastomers based on biopitch-PEG-MDI system. J Ther Anal Cal 2002; 67: 313-319.

[19] Criado JM, González M, Ortega A, Real C. Some consideration regarding the determination of the activation energy of solid-state reaction from a series of isothermal data. Thermochim Acta 1984; 29: $243-250$.

[20] Vlase T, Vlase G, Chiriac A, Doca N. The influence of concentration and anion nature on the support effect. J Therm Anal Cal 2003; 72: 847-853.

[21] Liu N, Zong R, Shu L, Zhou J, Fan W. Kinetic compensation of effect in thermal decomposition of cellulosic materials in air atmosphere. J Appl Pol Sci 2003; 89: 135-141.

[22] Pelichowski K, Kulesza K, Pearce E. Thermal degradation studies on rigid polyurethanes foams blown with pentane. J Appl Pol Sci 2003; 88: 2319-2330.

[23] Chuang FS, Tsen WC, Shu YC. The effect of different siloxane chain-extenders on thermal degradation and stability of segmented polyurethanes. Pol Deg Stab 2004; 84: 69-77.

[24] Klarić I, Roje U, Stipanelov N. Kinetic investigation of thermooxidative degradation of poly (vinyl chloride)/acrylonitrilebutadiene-styrene blends by isothermal Thermogravimetric analysis. J Appl Pol Sci 1999; 71: 833-839.

[25] Klarić I, Roje U, Kovacic T. Kinetic of thermal degradation of PVC/ABS blends. J Therm Anal 1995; 45: 1373-1380.

[26] Duwenhorst, J., Malz, H., Scheffer, K., Flug, T., Vallo, M.: EP1877460 (2008).

[27] O’Sickey M. PhD Thesis Characterization of structure-property relationships of poly(urethane-urea)s for fiber applications, Virginia Polytechnic, Virginia, 2002; Chapter 1-2.

[28] De Britto, Campana-Filho S. A kinetic study on the thermal degradation of $N, N, N$-trimethylchitosan. Pol Deg Stab 2004; 84: 353-361. 